\title{
Perbedaan Pola Konsumsi Junk Food pada Remaja Putri SMP Daerah Perkotaan dan Pedesaan terhadap Kejadian Menarche Dini
}

\author{
Kustin ${ }^{1}$ \\ STIKES dr. Soebandi Jember, Indonesial \\ e-mail : kustinhariyono@gmail.com
}

\begin{abstract}
The transition between childhood and adulthood is the period of puberty. An important event in puberty is rapid body growth, the appearance of secondary sex features, menarche, and psychic changes. Menarche is too early to be associated with risk factors for some malignant disease such as ovarian cancer, breast cancer, and myoma. Hyperplasia cholecystitis, incidence of uterine cancer and risk of Non Insulin Dependent Diabetes Mellitus (NIDDM / Type II) as adults. The purpose of this research is to analyze the consumption effect on junk food to early puberty in teenages in junior high school urban and rural area in Jember Regency. This research was a quantitative research with cross sectional and laboratory design using pre experimental design with one shot case study approach for food samples most often consumed. The sample are teenage girls who student in junior high school, 88 tenages from urban and 88 tenages from rural in Jember Regency. Data analysis was processed using logistic regression test of significance level $p<0.05$. Result showed that there was a significant effect between junk food consumption pattern on early puberty statistically $p=0.000<0.05$ for urban and rural junior high school. Laboratory results also show that the fat content of junk food averages over 20\%. The conclusion is that consumption habits, consumption time and the amount of fat consumed from junk food affect the incidence of early puberty in young women while the frequency of consumption does not affect the incidence of early puberty.
\end{abstract}

Keywords: early puberty, fat, junk food.

\section{Pendahuluan}

Masa peralihan antara masa kanakkanak dan masa dewasa merupakan masa pubertas. Tidak ada batas yang tajam antara akhir masa kanak-kanak dan awal masa pubertas, akan tetapi dapat dikatakan bahwa masa pubertas diawali dengan berfungsinya ovarium. Kejadian yang penting dalam pubertas ialah pertumbuhan badan yang cepat, timbulnya ciri-ciri kelamin sekunder, menarche dan perubahan psikis (Widyastuti, 2009). Menarche terlampau dini dikaitkan dengan faktor risiko beberapa penyakit keganasan. Menurut Helm (2009), usia menarche dini merupakan faktor risiko terjadinya kanker ovarium, kanker payudara dan mioma. Hal ini senada dengan hasil penelitian yang dilakukan oleh Al Shahab (2010) bahwa menarche yang terlalu cepat meningkatkan resiko terjadinya kanker payudara dan juga kanker ovarium (Rah, 2009). Di samping itu, percepatan usia menarche juga memperbesar peluang terjadinya hiperplasia endometrium (Chiang, 2008). Menurut Hebra (2008), kolesistitis juga berkaitan dengan usia menarche yang lebih cepat. Belakangan, insiden kanker uterus dan kanker payudara juga dihubungkan dengan usia menarche (Chiang,
2009; Swart, 2010) oleh alasan hormonal, yang dalam hal ini lebih didominasi oleh estrogen. Penelitian yang dilakukan oleh Chunyan (2009) menunjukkan bahwa usia menarche memiliki resiko terjadinya Diabetes Mellitus tipe 2 saat dewasa.

Kecenderungan usia menarche yang semakin dini juga berimplikasi pada risiko terjadinya kehamilan pada usia yang lebih muda (Rah, 2009) dan perpanjangan waktu persalinan (MacKibben, 2003).

Salah satu faktor pemicu Menarche dini(menarche) ini adalah status gizi lebih atau obesitas dimana obesitas bisa disebabkan karena mengkonsumsi makanan yang tinggi kalori serta lemak yang termasuk jenis junk food. Kandungan lemak khususnya trans lemak dalam junk food ini akan merangsang produksi hormon yang berperan dalam pematangan folikel dan pembentukan estrogen. Hormon estrogen inilah yang berperan dalam perkembangan tanda-tanda pubertas baik primer maupun sekunder.

\section{Metode}

Jenis penelitian ini kuantitatif menggunakan observasional Analitik dengan 
desain Cross Sectional Study dan eksperimental untuk uji sampel makanannya.

\subsection{Metode Pengumpulan Data}

Penelitian dilakukan di Sekolah Menengah Pertama (SMP) daerah Pedesaan dan perkotaan Kabupaten jember. Pengambilan sampel dilakukan dengan cara cluster random sampling untuk menentukan unit populasi. Dari unit populasi diambil sebesar 20\% (Wahab, 2013) secara random sampling dan proporsional sehingga didapatkan sample 88 untuk SMP daerah perkotaan dan 88 untuk SMP daerah Pedesaan. Instrumen penelitian yang digunakan adalah kuesioner dan uji sampel makanan dilaboratorium.

\subsection{Metode Analisis Data}

Pengolahan data dilakukan dengan tabulasi dan analisis data dilakukan dengan uji statistik menggunakan regresi logistik dengan tingkat kemaknaan $95 \%(\alpha=0,05)$.

\section{Hasil dan Pembahasan}

Hasil penelitian menunjukkan distribusi usia remaja putri adalah sebagai berikut :

Tabel 1 menunjukkan hasil penelitian yaitu distribusi karakteristik responden berdasarkan usia baik dari SMP yang ada didaerah perkotaan maupun pedesaan.

Tabel 1 : Distribusi karakteristik usia responden di smp daerah perkotaan dan pedesaan di kabupaten Jember

\begin{tabular}{llcccc}
\hline No & Usia responden & \multicolumn{2}{c}{ SMP Perkotaan } & \multicolumn{2}{c}{ SMP Pedesaan } \\
\cline { 3 - 6 } & & f & \% & f & \% \\
\hline 1 & 12 tahun & 5 & 5,68 & 1 & 1,14 \\
2 & 13 tahun & 54 & 61,36 & 65 & 73,86 \\
3 & 14 tahun & 26 & 29,54 & 21 & 23,86 \\
4 & 15 tahun & 3 & 3,42 & 1 & 1,14 \\
\hline \multicolumn{2}{l}{ Jumlah } & 88 & 100 & 88 & 100 \\
\hline
\end{tabular}

Sumber : Data Primer, 2018

Tabel 2 menunjukkan hasil penelitian status Menarche diniyang dialami oleh responden baik SMP daerah perkotaan maupun pedesaan.

Tabel 2 : Distribusi responden berdasarkan status menarche dini

\begin{tabular}{llccccc}
\hline \multirow{2}{*}{ No } & $\begin{array}{c}\text { Status Menarche } \\
\text { dini(Menarche) }\end{array}$ & \multicolumn{2}{c}{ SMP Pedesaan } & \multicolumn{2}{c}{ SMP Perkotaan } \\
\cline { 3 - 6 } & f & f & \% & f & \% \\
\hline 1 & Menarche dini & 60 & 68,18 & 67 & 76,13 \\
2 & Normal & 28 & 31,82 & 21 & 23,87 \\
\hline Jumlah & 88 & 100 & 88 & 100 \\
\hline
\end{tabular}

Sumber : Data Primer, 2018

Tabel 3 menunjukkan hasil penelitian distribusi responden berdasarkan pola konsumsi junk food pada responden baik pada SMP daerah perkotaan maupun pedesaan. Tabel 4 menunjukkan hasil penelitian frekuensi konsumsi junk food padaresponden.

Tabel 3 : Distribusi responden berdasarkan pola konsumsi Junk Food

\begin{tabular}{cccccc}
\hline \multirow{2}{*}{ No } & $\begin{array}{c}\text { Pola Konsumsi Junk } \\
\text { Food }\end{array}$ & \multicolumn{2}{c}{ SMP Pedesaan } & \multicolumn{2}{c}{ SMP Perkotaan } \\
\cline { 3 - 6 } & Konsumsi Junk Food & 67 & $\mathbf{f}$ & f & \% \\
\hline 1 & Konsumsi Non Junk Food & 21 & 76,13 & 72 & 81,81 \\
2 & 88 & 100 & 88 & 18,19 \\
\hline Jumlah & \multicolumn{3}{c}{}
\end{tabular}


Tabel 4 : Distribusi responden berdasarkan frekuensi konsumsi junk food

\begin{tabular}{llcccc}
\hline \multirow{2}{*}{ No } & \multirow{2}{*}{ Frekuensi Konsumsi Junk Food } & \multicolumn{2}{c}{ SMP Pedesaan } & \multicolumn{2}{c}{ SMP Perkotaan } \\
\cline { 3 - 5 } & & f & \% & f & \% \\
\hline 1 & Sering (1X sehari)/4-6 kali seminggu & 33 & 37,50 & 44 & 50,00 \\
2 & Biasa (3 kali per minggu) & 34 & 38,63 & 36 & 40,90 \\
$3 . \quad$ Kadang-kadang (<3X per minggu)/ & 18 & 20,45 & 5 & 5,68 \\
& 1-2 kali per minggu & 3 & 3,42 & 3 & 3,42 \\
4. Jarang (1 kali seminggu) & 88 & 100 & 88 & 100 \\
\hline \multicolumn{2}{l}{ Jumlah }
\end{tabular}

Tabel 5 menunjukkan hasil penelitian data waktu responden mengkonsumsi junk food pada remaja puti SMP baik daerah perkotaan maupun pedesaan.

Tabel 5 : Distribusi responden berdasarkan waktu konsumsi junk food

\begin{tabular}{llcccc}
\hline \multirow{2}{*}{ No } & Waktu Konsumsi Junk Food & \multicolumn{2}{c}{ SMP Pedesaan } & \multicolumn{2}{c}{ SMP Perkotaan } \\
\cline { 3 - 6 } & & f & \% & f & \% \\
\hline 1. & Siang hari $(06.00-18.00)$ & 65 & 73,86 & 55 & 62,50 \\
2. & Malam hari $(>18.00)$ & 23 & 26,14 & 33 & 37,50 \\
\hline Jumlah & 88 & 100 & 88 & 100 \\
\hline Sumber $:$ Data Primer, 2018 & \multicolumn{4}{c}{}
\end{tabular}

Tabel 6 menunjukkan hasil penelitian distribusi responden berdasarkan prosentase besaran lemak junk food yang dikonsumsi oleh responden. Tabel 7 menunjukkan hasil uji statistik pengaruh konsumsi junk food terhadap kejadian menarche.

Tabel 6 : Distribusi responden berdasarkan prosentase besaran lemak junk food yang dikonsumsi terhadap lemak total

\begin{tabular}{llcccc}
\hline No & $\begin{array}{c}\text { Prosentase lemak junk } \\
\text { food }\end{array}$ & \multicolumn{2}{c}{ SMP Pedesaan } & \multicolumn{2}{c}{ SMP Perkotaan } \\
\cline { 3 - 6 } & & f & \% & fi & $\%$ \\
\hline 1. & Tinggi $(>10 \%)$ & 60 & 68,18 & 73 & 82,95 \\
2. & Rendah $(<10 \%)$ & 28 & 31,82 & 15 & 17,05 \\
\hline Jumlah & 88 & 100 & 88 & 100 \\
\hline
\end{tabular}

Sumber : Data Primer, 2018

Tabel 7 : Hasil uji statistik pengaruh konsumsi junk food terhadap menarche

\begin{tabular}{|c|c|c|c|c|c|c|c|c|c|c|c|}
\hline \multirow{4}{*}{ No } & \multirow{4}{*}{$\begin{array}{l}\text { Konsumsi } \\
\text { Junk food }\end{array}$} & \multicolumn{10}{|c|}{ Status Menarche } \\
\hline & & \multicolumn{5}{|c|}{ SMP Pedesaan } & \multicolumn{5}{|c|}{ SMP Perkotaan } \\
\hline & & \multicolumn{2}{|c|}{ Menarche dini } & \multicolumn{2}{|c|}{ normal } & & \multicolumn{2}{|c|}{ Menarche dini } & \multicolumn{2}{|c|}{ Normal } & \multirow{2}{*}{ Sign } \\
\hline & & $\mathbf{n}$ & $\%$ & $\mathbf{n}$ & $\%$ & & $\mathrm{n}$ & $\%$ & $\mathrm{n}$ & $\%$ & \\
\hline 1. & Konsumsi & 53 & 68,18 & 7 & 7,95 & \multirow{2}{*}{0,000} & 60 & 68,18 & 12 & 13,63 & \multirow{2}{*}{0,000} \\
\hline 2. & Tidakkonsumsi & 7 & 7,95 & 21 & 23,86 & & 7 & 7,95 & 9 & 10,22 & \\
\hline & Jumlah & 60 & & 28 & & & 67 & & 21 & 100 & \\
\hline
\end{tabular}

Sumber : Data Primer, 2018

Tabel 8 menunjukkan hasil penelitian uji statistik frekuensi konsumsi junk food terhadap kejadian menarce dini.

Tabel 8 : Tabel frekuensi konsumsi junk food terhadap kejadian menarche dini 
ISSN : 2354-5852

e-ISSN : 2579-5783

\begin{tabular}{|c|c|c|c|c|c|c|c|c|c|c|}
\hline \multirow{4}{*}{$\begin{array}{l}\text { Frekuensi Konsumsi } \\
\text { Junk Food }\end{array}$} & \multicolumn{10}{|c|}{ Status menarche dini } \\
\hline & \multicolumn{5}{|c|}{ SMP Pedesaan } & \multicolumn{5}{|c|}{ SMP Perkotaan } \\
\hline & \multicolumn{2}{|c|}{ Menarche dini } & \multicolumn{2}{|c|}{ Normal } & \multirow{2}{*}{ Sig } & \multicolumn{2}{|c|}{ Menarche dini } & \multicolumn{2}{|c|}{ Normal } & \multirow[b]{2}{*}{ Sig } \\
\hline & $\mathbf{n}$ & $\%$ & $\mathbf{n}$ & $\%$ & & $\mathbf{n}$ & $\%$ & $\mathbf{n}$ & $\%$ & \\
\hline $\begin{array}{l}\text { Sering (1X sehari)/4-6 } \\
\text { kali seminggu }\end{array}$ & 40 & 45,45 & 4 & 4,55 & & 28 & 31,81 & 5 & 5,68 & \\
\hline $\begin{array}{l}\text { Biasa ( } 3 \text { kali per } \\
\text { minggu) }\end{array}$ & 26 & 29,55 & 10 & 11,36 & & 22 & 25 & 12 & 13,63 & \\
\hline $\begin{array}{l}\text { Kadang-kadang }(<3 X \\
\text { per minggu }) / 1-2 \text { kali } \\
\text { per minggu }\end{array}$ & 1 & 1,13 & 4 & 4,55 & 0,459 & 10 & 11,36 & 8 & 9,09 & 0,484 \\
\hline $\begin{array}{l}\text { Jarang ( } 1 \text { kali } \\
\text { seminggu })\end{array}$ & 0 & 0 & 3 & 3,41 & & 0 & 0 & 3 & 3,41 & \\
\hline Jumlah & 67 & & 21 & & & 60 & & 28 & & \\
\hline
\end{tabular}

Sumber : Data Primer, 2018

Tabel 9 menunjukkan hasil penelitian uji statsitik waktu konsumsi junk food terhadap kejadian menarche dini pada responden

Tabel 9: Hasil uji statistik pengaruh waktu konsumsi junk food terhadap menarche dini

\begin{tabular}{|c|c|c|c|c|c|c|c|c|c|c|c|}
\hline \multirow{4}{*}{ No } & \multirow{4}{*}{$\begin{array}{l}\text { Konsumsi } \\
\text { Junk food }\end{array}$} & \multicolumn{10}{|c|}{ Status $M$ enarche dini } \\
\hline & & \multicolumn{5}{|c|}{ SMP Pedesaan } & \multicolumn{5}{|c|}{ SMP Perkotaan } \\
\hline & & \multicolumn{2}{|c|}{ Menarche dini } & \multicolumn{2}{|c|}{ Normal } & \multirow{2}{*}{ Sig } & \multicolumn{2}{|c|}{ Menarche dini } & \multicolumn{2}{|c|}{ Normal } & \multirow[t]{2}{*}{ Sig } \\
\hline & & $\mathrm{n}$ & $\%$ & $\mathbf{n}$ & $\%$ & & $\mathrm{n}$ & $\%$ & $\mathbf{n}$ & $\%$ & \\
\hline 1 & $\begin{array}{l}\text { Siang hari }(06.00- \\
18.00)\end{array}$ & 50 & 56,81 & 15 & 17,04 & \multirow{2}{*}{0,027} & 51 & 57,95 & 4 & 4,54 & \multirow{2}{*}{0,003} \\
\hline 2 & $\begin{array}{l}\text { Malam hari }(> \\
18.00)\end{array}$ & 17 & 19,32 & 6 & 6,81 & & 9 & 10,22 & 24 & 27,27 & \\
\hline & Jumlah & 67 & & 21 & & & 60 & & 28 & & \\
\hline
\end{tabular}

Sumber : Data Primer, 2018

Tabel 10 menunjukkan hasil food dari total lemak terhadap kejadian penelitian pengaruh prosentase lemak junk menarche dini pada responden.

Tabel 10 : Hasil uji statistik pengaruh prosentase besaran lemak junk food yang dikonsumsi dari lemak total terhadap menarche dini

\begin{tabular}{|c|c|c|c|c|c|c|c|c|c|c|c|}
\hline \multirow{4}{*}{ No } & \multirow{4}{*}{$\begin{array}{l}\text { Konsumsi } \\
\text { Junk food }\end{array}$} & \multicolumn{10}{|c|}{ Status $M$ enarche dini } \\
\hline & & \multicolumn{5}{|c|}{ SMP Pedesaan } & \multicolumn{5}{|c|}{ SMP Perkotaan } \\
\hline & & \multicolumn{2}{|c|}{$\begin{array}{c}\text { Menarche } \\
\text { dini }\end{array}$} & \multicolumn{2}{|c|}{ Normal } & \multirow[t]{2}{*}{ Sig } & \multicolumn{2}{|c|}{$\begin{array}{c}\text { Menarche } \\
\text { dini }\end{array}$} & \multicolumn{2}{|c|}{ Normal } & \multirow[t]{2}{*}{ Sig } \\
\hline & & n & $\%$ & n & $\%$ & & $\mathbf{n}$ & $\%$ & n & $\%$ & \\
\hline 1. & Tinggi $(>10 \%)$ & 51 & 57,95 & 9 & 10,22 & 0,005 & 61 & 69,31 & 12 & 13,63 & 0,026 \\
\hline \multirow[t]{2}{*}{2.} & Rendah $(<10 \%)$ & 16 & 18,18 & 12 & 13,63 & & 9 & 10,22 & 6 & 6,81 & \\
\hline & Jumlah & 67 & & 21 & & & 70 & & 18 & & \\
\hline
\end{tabular}


Untuk mengetahui faktor apa saja yang memiliki pengaruh signifikan terhadap pubertas dini (menarche) pada remaja putri dapat diketahui dengan melakukan uji multivariate menggunakan uji statistik regresi logistik, dimana metode ini digunakan untuk mengetahui ada tidaknya pengaruh variable bebas terhadap variable terikat dengan syarat variable terikat mempunyai skala data nominal. Syarat pengambilan keputusan dilakukan dengan menggunakan $p$-value, di mana $p$-value yang lebih kecil dari alpha $(0,05)$ menunjukkan bahwa terdapat pengaruh signifikan antara variabel bebas terhadap variable terikat, seperti yang ditampilkan pada tabel 11 .

Tabel 11: Hasil uji statistik pengaruh konsumsi junk food terhadap menarche dini

\begin{tabular}{lcccc}
\hline \multirow{2}{*}{ Variabel penelitian } & \multicolumn{3}{c}{ Hasil Uji Regresi logistik (nilai p-value) } \\
\cline { 2 - 5 } & $\begin{array}{c}\text { SMP daerah } \\
\text { perkotaan }\end{array}$ & Sig & $\begin{array}{c}\text { SMP daerah } \\
\text { Pedesaan }\end{array}$ & Sig \\
\hline $\begin{array}{l}\text { PolaKonsumsi junk } \\
\text { food }\end{array}$ & 0,000 & Signifikan & 0,000 & Signifikan \\
$\begin{array}{l}\text { Frekuensikonsumsi } \\
\text { junk food }\end{array}$ & 0,459 & Tidaksignifikan & 0,484 & Tidaksignifikan \\
$\begin{array}{l}\text { Waktukonsumsi junk } \\
\text { food }\end{array}$ & 0,027 & Signifikan & 0,003 & Signifikan \\
Prosentasebesaranlemak & 0,005 & Signifikan & 0,026 & Signifikan \\
\hline
\end{tabular}

Sumber : Data Primer, 2018

Hasil analisis pengaruh pola konsumsi terhadap Menarche dini pada remaja putri di SMP daerah pedesaan dan Perkotaan Kabupaten Jember menunjukkan bahwa sebanyak 72 responden $(81,81 \%)$ mengalami Menarche dini untuk SMP daerah perkotaan dan sebanyak 76 responden $(76,13 \%)$ juga mengalami Menarche dini untuk responden di SMP daerah pedesaan Kabupaten Jember. Sedangkan hasil analisis menggunakan regresi logistik menunjukkan bahwa ada pengaruh yang signifikan antara pola konsumsi junk food terhadap Menarche dini baik pada remaja putri di SMP daerah perkotaan maupun pedesaan. Hal ini sejalan dengan penelitian yang dilakukan oleh Madityas (2015) menyatakan bahwa kebiasaan mengkonsumsi junk food di kalangan anak-anak modern akan mempengaruhi peningkatan gizi. Hal ini disebabkan karena kandungan lemak, protein hewani, dan trans lemak yang terdapat dalam junk food akan memicu pengeluaran hormon-hormon yang berpengaruh terhadap terjadinya menarche dan timbulnya tandatanda sekunder pada anak -anak lebih cepat dari usia normal. Timbulnya tanda-tanda pubertas baik primer maupun sekunder sebelum umur 8 tahun dan terjadinya menarche sebelum usia 11 tahun disebut dengan Menarche dini. Hal ini sejalan dengan penelitian yang dilakukan oleh Madityas (2015) menyatakan bahwa kebiasaan mengkonsumsi junk food di kalangan anakanak modern akan mempengaruhi peningkatan gizi. Hal ini disebabkan karena kandungan lemak, protein hewani, dan trans lemak yang terdapat dalam junk food akan memicu pengeluaran hormon-hormon yang berpengaruh terhadap terjadinya menarche dan timbulnya tanda-tanda sekunder pada anak -anak lebih cepat dari usia normal. Timbulnya tanda-tanda pubertas baik primer maupun sekunder sebelum umur 8 tahun dan terjadinya menarche sebelum usia 11 tahun disebut dengan menarche dini.

Hasil analisis pengaruh frekuensi konsumsi junk food terhadap menarche dini pada remaja putri di SMP daerah pedesaan dan Perkotaan Kabupaten Jember menunjukkan bahwa sebanyak 44 responden $(50 \%)$ mengkonsumsi dengan frekuensi sering (1 kali sehari) / 4-6 kali seminggu untuk SMP, sebanyak 36 responden $(40,90 \%)$ mengkonsumsi dengan frekuensi biasa (3 kali per minggu), sebanyak 5 responden $(5,68 \%)$ frekuensi mengkonsumsi kadang-kadang $(<3$ kali per minggu) / 1-2 kali per minggu dan sebanyak 3 responden $(3,42 \%)$ dengan frekuensi mengkonsumsi 
junk food jarang (1 kali per minggu) untuk SMP daerah perkotaan. Sedangkan untuk SMP daerah pedesaan di dapatkan hasil sebanyak 34 responden $(38,63 \%)$ frekuensi mengkonsumsi biasa (3 kali per minggu), sebanyak 33 responden $(37,50 \%)$ dengan frekuensi sering (1 kali sehari) / 4-6 kali per minggu, sebanyak 18 responden (20,45\%) ( $<3$ kali per minggu) / 1-2 kali per minggu dan 3 reponden $(3,42 \%)(<3$ kali per minggu) / 1-2 kali per minggu. Frekuensi banyaknya jenis makanan yang tersedia di pasaran sehingga memudahkan bagi orang tua dalam dalam menyajikan makanan junk food. Selain itu banyaknya jajanan junk food yang dijual dilingkungan sekolah juga membuat anak menjadi lebih sering mengkonsumsi junk food. Makanan junk food terdiri dari dua jenis yaitu junk food local dan juga jenis junk food dari Negara lainya itu dari barat (western junk food) atau disebut junk food modern. Umumnya makanan junk food termasuk jenis makanan yang mengandung tinggi energi, lemak dan rendah serat. Jenis junk food yang paling sering dikonsumsi adalah dari jenis fried chicken, gorengan, makanan dari daging olahan (bakso, nugget) serta cookies. Kebiasaan makan remaja yang tidak teratur, sering jajan, sering tidak sarapan, sehingga tidak jarang para remaja lebih sering mengkonsums junk food.

Hasil peneltian menunjukkan bahwa berdasarkan waktu konsumsi junk food pada SMP daerah perkotaan didapatkan sebanyak 55 responden $(62,50 \%)$ remaja putri mengkonsumsi junk food pada siang hari yakni pada pukul 06.00-18.00 dan sebanyak 33 responden $(37,50 \%)$ mengkonsumsi pada waktu malam hari yaitu pukul $>18.00$. Sedangkan pada SMP daerah pedesaan didapatkan hasil sebanyak 65 responden $(73,86 \%)$ mereka mengkonsumsi pada siang hari dan seabnyak 23 responden $(26,14 \%)$ mengkonsumsi pada malam hari yaitu $>$ jam 18.00. Waktu mengkonsumsi makan junk food lebih banyak terjadi pagi atau siang hari. Hal ini dikarenakan pada pagi hari mereka mengkonsumsi sebagai sarapan pagi, dimana kebanyakan dari remaja putri yang mengkonsumsi pagi khususnya SMP daerah perkotaan dikarenakan kebanyakan dari orang tua mereka bekerja sehingga makanan yang dikonsumsi cenderung makanan cepat saji. Waktu makan pagi sebagai bentuk sarapan merupakan makanan yang berpengaruh untuk perkembangan otak. Dalam sebuah penelitian menunjukkan bahwa sarapan berhubungan erat dengan kecerdasan mental. Sehingga memberikan nilai positif terhadap aktivitas otak, menjadi lebih cerdas, peka dan mudah konsentrasi. Sebuah survei membuktikan anak dan remaja yang sarapan dengan yang kaya karbohidrat akan lebih bersemangat, mampu mencurahkan perhatian pada pelajaran, ceria, kooperatif dan gampang berteman (Larega, 2015)

Hasil penelitian menunjukkan bahwa prosentase besaran lemak yang dikonsumsi dari junk food terhadap lemak total adalah pada responden SMP daerah perkotaan sebanyak 73 responden $(82,95 \%)$ prosentase mengkonsumsi tinggi yakni lebih dari $10 \%$ sedangkan sebanyak 15 responden $(17,05 \%)$ prosentase mengkonsumsi rendah $<10 \%$. Sedangkan pada responden SMP daerah pedesaan di dapatkan hasil sebanyak 60 responden $\quad(68,18 \%) \quad$ prosentase mengkonsumsi tinggi $(>10 \%)$ sedangkan sebanyak 28 responden $(31,82 \%)$ prosentase mengkonsumsi rendah (<10\%). Asupan lemak berasal dari rata-rata asupan lemak yang dikonsumsi dan dinyatakan dalam persen, berasal dari makanan dan minuman. Asupan lemak dalam satu hari dihasilkan dari asupan makanan atau minuman yang dikonsumsi pada saat pagi hingga malam hari sebelum dilakukan recall. Dalam penelitian Tuminah (2009), asupan lemak jenuh yang melebihi anjuran dapat meningkatkan kolesterol LDL dan kolesterol total dalam darah. Asupan lemak yang dianjurkan menurut PUGS adalah $10-25 \%$ dari total kebutuhan energi dalam sehari, dan $<10 \%$ berasal dari lemak jenuh. Konsumsi sumber asam lemak jenuh yang berlebihan merupakan penyebab terjadinya dislipidemia (Devi, 2010). Asupan lemak yang tinggi atau lebih dari sepertiga total kalori pada umumnya meningkatkan asupan lemak jenuh dan berhubungan dengan kelebihan berat badan dan kalori. Kelebihan lemak diatas $20 \%$ dalam tubuh juga dapat menimbulkan permasalahan klinis.

\section{Kesimpulan dan Saran}


Kesimpulan dari peneltian ini adalah kebiasaan mengkonsumsi junk food (pola dan jenis konsumsi, waktu dan prosentase besaran lemak yang dikonsumsi dari junk food) mempengaruhi kejadian Menarche dinisedangkan frekuensi konsumsi junk food tidak mempengaruhi kejadian menarche dini. Menarche dini lebih awal menyebabkan resiko penyakit keganasan (kanker ovarium, kanker payudara dan mioma, hiperplasia endometrium, kolesistisis, resiko kehamilan tidak diinginkan dan psikis yang belum siap). Oleh karena itu perlunya peningkatan upaya promotif dan preventif melalui pendidikan kesehatan kepada keluarga terutama dampak dari konsumsi junk food terhadap kejadian menarche dini

\section{Ucapan Terima Kasih}

Terima kasih kepada instansi saya bekerja STIKES dr. Soebandi Jember atas support sistem dan pendanaan dalam kegiatan penelitian ini dan semoga ke depan bisa lebih bisa meningkatkan kontribusi kami lebih besar lagi.

\section{Daftar Pustaka}

Chiang, J. (2008) Premalignant Lesions of the Endometrium. Available at: http://www.emedicine.com.

Chiang, J. (2009) Uterine Cancer. Available at: http://www.emedicine.com.

Chunyan, H. (2009) 'Age at Menarche and Risk of Type 2 Deabetes: result From 2 Large Prospektif Cohort Studies', American Jurnal of Epedemiologi, 171, pp. 334-344. Available at: http://aje.oxfordjournals.org/content/1 $7 / 3 / 334$.

Devi, N. (2010) Nutrition and Food. Jakarta: Penerbit Buku Kompas.

Hebra, A. (2008) Cholecystitis. Medical University of South Carolina.

Helm, C. (2009) Ovarian Cyst. University of Louisville. Available at: http://emedicine.com.

Larega, T. (2015) 'Pengaruh Sarapan Terhadap Tingkat Konsentrasi pada Remaja', Jurnal Fakultas Kedokteran
Uviversitas Lampung J MAJORITY, 4(2).

MacKibben, S. (2003) The Social Construction of Adulthood: Menarche and Motherhood. USA: Texas A\&M University.

Madityas, G. (2015) 'Konsumsi Junk Food dan Pubertas Dini', Jurnal Mayority, 4(8). Available at: ukeunila.com/wp_CONTENT/UPLO ADS/2015/11/117-120-genoveva.

Rah, J. (2009) 'Age of Onset, Nutritional Determinants, and Seasonal Variation in Menarche in Rural Bangladesh', $J$ Health Popul Nutr. Available at: http://centre.icddrb.org/image/1228Jee_Rah.pdf.

Swart, R. (2010) Breast Cancer. Available at: http://emedicine.medscape.com/article /283561-overview (Accessed: 12 June 2017).

Tuminah, S. (2009) 'Efek Asam Lemak Jenuh dan Asam Lemak tak Jenuh Trans Terhadap Kesehatan', Media Penelitian dan Pengembang Kesehatan. Suplemen II. Gizi Indonesia, XIX.

Wahab, A. (2013) Pengantar Riset Bidang Kesehatan, Kebidanan dan Keperawatan. Yogyakarta: Kaukaba.

Widyastuti, Y. (2009) Kesehatan Reproduksi. Yogyakarta: Fitrimaya. 